\title{
Corpus de cuentos folklóricos de enigmas (o de adivinanzas)
}

Registro: Estos cuentos fueron recopilados durante 1985 y 1986 en sectores rurales de Osorno (sur de Chile), en el marco de una investigación más amplia sobre tradición oral, por el grupo de estudio integrado por Constantino Contreras, Eduardo Barraza, Pilar Álvarez-Santullano y Lilian Rodríguez.

Transcripción y notas lingüísticas: Constantino Contreras (de la Universidad de La Frontera, Temuco) y Eduardo Barraza (de la Universidad de Los Lagos, Osorno).

\section{ADIVINANZA DE ANA}

Narradora: Rosa Amelia Bustamante Valderas (68 años)

Localidad: Dollinco (comuna de Purranque).

Esa adivinanza dice:

Ana fue hija,

Ana fue madre,

mantuvo hijo ajeno,

marido de su madre.

Entonces, éste era un caballero que tenía una sola hija. Y entonces esa hija estaba criando una guagua ${ }^{1}$. Y cayó preso. $\mathrm{Y}$ antes, los apresa(d)os ${ }^{2}$, no era como ahora que les dan de comer; antes no les daban de comer. Así que ella no hallaba cómo hacerlo cuando iba a la reja ${ }^{3}$ a ver a su padre. Ella lloraba junto al padre:

- ¿Cómo lo haré?

Cuando ya ella vio que su padre estaba quedando tan debilita(d)o de estar preso, entonces por entremedio de la reja sacaba el seno y le daba de mamar a su padre. Ése es el contenido de la adivinanza. Le daba de mamar y el papá se mantenía con el alimento de la hija. Por eso lo sacó el juez, le dijo:

- Mira, si tú me decís ${ }^{4}$ una adivinanza que yo no la adivine, vas a salir libre.

1 guagua: en Chile y países vecinos 'niño recién nacido hasta más o menos un año de edad', voz procedente del quechua (cfr. ACADEmia ChILENa Correspondiente de la Real Academia Española, Diccionario del habla chilena, Santiago de Chile, Editorial Universitaria, 1978, p. 119. En adelante $\mathrm{DHCH}$ ).

2 Es frecuente el debilitamiento o pérdida de - $d$ - especialmente en las terminaciones -ado, -ido. Utilizamos los paréntesis para señalar los casos similares de debilitamiento fónico o de franca elisión.

3 reja: 'enrejado de la cárcel' o la misma 'cárcel' (cfr. DHCH, p. 197).

4 decís: forma verbal voseante, no frecuente en estas narraciones. 
Entonces él no hallaba cómo hacerlo. Porque en los libros qué adivinanza no hay, pu(es). Tienen todo el contenido. Ése es el mismo hecho de él, las mismas exper(i)encias que él estaba haciendo. Entonces ésas las sacó de adivinanza. La(s) sacó en esa forma.

\section{LOS PEDIDOS DEL REY}

Narrador: Efraín Hernández Paredes (68 años)

Localidad: Dollinco (comuna de Purranque).

Porque antes el rey... lo que decía el rey se hacía, tenía que hacerse. Bueno. Y tenía un inquilino. El veterano ${ }^{5}$, ése, tenía tres hijas, mujeres. Y un día jno se le ocurre al rey de hacerle un pedido!: que le llevara las hijas a presentárselas a él, preña(d)as, doncellas, calza(d)as y descalzas, de a pie y de a caballo, peina(d)as $y$ sin peinarse.

Cuando llegó el veterano a la casa, triste pu(e)s, porque desde luego que le hacía ese pedido que era imposible, pu(es), par(a) que él lo "hague" 6 .

- ¿Cómo va a ser que mis hijas van a ir preña(d)as y doncellas, calza(d)as y descalzas, de a pie y de a caballo, peina(d)as y sin peinarse?

Ahí (es)tuvo como una semana, triste, que ya no comía ni... no hacía nada, triste no más pu(es), pensando que iba a entregar la cabeza; porque el rey, cuando ya no lo hacían, bueno, se te iba la cabeza, porque ya no lo ha hecho. Entonces una de las hijas mayores le pregunta que por qué está así, triste.

- ¿Qué sacaré de decirte a ti cuando nada vas a remediar? - le dijo.

Llegó la otra del medio y le dice igual, le hace la pregunta: que por qué estaba tan triste, por qué no le decía las cosas que él sentía.

Bueno. Que le dijo:

- ¿Qué saco de decirte a ti cuando tú nada vas a remediar? Nada me puedes dar una respuesta bien buena.

Como siempre un padre, "u" sea la madre, tiene un hijo que lo quiere más, ¿ah? Y, como ésa era la menor, va y le dice:

- Yo voy a ir, le voy a preguntar. A ver, a mí me va a tener que decir esas cosas que él siente.

Y le va a preguntar.

- ¿Qué sacaré de decirte, hija? —es que ${ }^{7}$ le dijo-, cuando tú nada vas a remediar en eso.

- Sí, usted sabe, padre, que por lo menos muchas veces el que no sabe, ése da una respuesta mejor.

Entonces...:

-Yo te voy a decir, hija, a ti, porque a ti te quiero más. Mira, el rey me hizo un pedido: que la lleve a usted preña(d)a, doncella, calza(d)a y descalza, de a pie y de a caballo y peina(d)a y sin peinarse.

5 veterano: 'anciano' (cfr. $\mathrm{DHCH}$, p. 245).

6 "hague": alteración de la forma haga, utilizada aquí, en discordancia temporal, en vez de 'hiciera o hiciese'. Hay otros ejemplos similares en el texto.

7 es que: expresión equivalente a 'dicen que' o conservación de la antigua loc. adverbial diz que 'al parecer'. Es sumamente frecuente en las narraciones (cfr. Rodolfo Oroz, La lengua castellana en Chile, Facultad de Filosofía y Educación, Universidad de Chile, Santiago de Chile, Editorial Universitaria, 1966, p. 394). 
- ¡Uf! ¡Qué! -le dijo-. ¿Por eso no más está triste, padre? ¡Déjemelo a mí no más ese gallo ${ }^{8 !}$ ¡Conmigo se va a arreglar!

-Bueno, entonces. Ya.

- Déjemelo no más, no se le dé nada. No piense. Yo voy a hacer todo el trabajo, ése.

Se fue y tomó la máquina de coser y comenzó a hacerse más o menos un almohadoncito, así como un cojín, más o menos tanteando una altura que se conozca no más en la guatita ${ }^{9}$. ¿Ah? Y ésa se la puso, se la amarró ahí. Y hizo para... para ella y para las otras dos hermanas. Cuando ya estuvo lista, se fue ahí, al campo. Al lado de la casa no más "habían" ${ }^{10}$ unos coligües ${ }^{11}$. Se fue a cortar tres coligües y le(s) puso unas... unas pitas de rienda, a esos coligües; a una cabecita que le hizo prácticamente artificial le puso rienda. Cuando ella estuvo lista, le dijo:

-Bueno, padre, ahora nos vamos.

Y se puso no más que un zapato. Las tres. Les dijo a las otras hermanas que se pongan un zapato no más. Y la otra a pie pela(d)o. Y se peinen no más que a un solo lado. ¿Ah? Y ya las... las otras cositas, ésas, se... le(s) pasó a las hermanas. $\mathrm{Y}$ todas se fueron, que se conocía un poquito el embarazo nada más.

Bueno. Y se fue el padre a presentarse con sus hijas. Bueno, llegó allá. Claro, las miró: el pedido que le había hecho, exactamente como él lo había pedido.

Bueno, que le dijo la menor:

-Ahora - le dijo-, nosotros como "los" 12 encontramos en esta situación, así que andamos embarazadas, yo... a mí me dio deseo de comer, de servirme harina tosta(d)a con nieve.

Y el mozo echó a tostar la nieve. Y apenas echaba la nieve a la callana ${ }^{13}$, se "reitía" ${ }^{14}$. No la pudo hacer. Entonces de ahí le dijo el rey que no podía hacer..., porque se "reitía". ¿Cómo iba a tostar la nieve?

Ya, que la llamó a ella y le dice:

8 gallo: 'hombre fuerte, destacado, valiente' ( $\mathrm{DHCH}$, p. 115); pero también 'hábil', 'presumido', etc.

9 guatita: dim. de guata 'barriga, vientre, panza', voz de procedencia mapuche (cfr. DHCH, p. 121).

10 "habían": La pluralización de la forma impersonal babía es frecuente en el uso popular de Chile y otros países de habla hispana. Cfr. Charles KANY, Sintaxis hispanoamericana, versión española de Martín Blanco Álvarez (Madrid: Gredos, 1969), p. 256.

11 coligüe: nombre (procedente del mapuche) de la 'planta sureña de la familia gramíneas, con varas altas y articuladas mediante nudosidades'(Chusqueacouleu Desvaux) (cfr. DHCH, p. 79).

12 "los": "La sustitución de nos por los es una de las costumbres más arraigadas" en el español popular de nuestro país, según R. OROz, op. cit., p. 297.

13 callana: 'utensilio de greda o de metal para tostar trigo'; voz quechua, según Rodolfo LENZ, Diccionario etimológico de las voces chilenas derivadas de lenguas indigenas americanas (Santiago de Chile: Imprenta Cervantes, 1905-1910), p. 166; en adelante DICC. ETIM.

14 "reitía": alteración fónica, por metátesis, de la forma derretía (cfr. derretir > redetir > re(d)itir, en R. OROZ, op. cit., p. 160). 
-Tú vas a ser mi señora. Y nada más. Palabra de rey. Pero te voy a hacer un pedido - cuando ya llegó el civil ${ }^{15}$ y cura, en fin, a casarlo-. Pero te voy a hacer un pedido: que tú no te metas nunca en cosas que no te importan. ¿Eh?

- (Es)tá bien.

Y a él le dijo, al veterano, que se vaya a su casa. Ya quedó casa(d)o el rey. Y este rey tenía una propuesta: que el que pasase, ni que hubiese sido amaneciendo, tenía que pasar a alojar donde él. Y un cierto día pasaron unos caballeros: uno iba en un macho, es decir un... macho, claro; y el otro iba en una yegua. Y la yegua iba al parir. Entonces ahí en la noche ¡cómo no se le antoja a la yegua parir! Porque ahí habían pasado a alojar. Y éstos pasaron amaneciendo, pu(es). Y en la noche le antojó a la yegua parir. Y al otro día no... el potrillo no seguía na(d)a a la yegua, sino al caballo, pu(es). Ya comenzaron a alegar entre ellos. Y fueron (d)onde el rey...: que pasaba eso, que su yegua había parido y el potrillo seguía al caballo.

-Bueno - es que le dijo-, bueno -es que dijo el rey-, el potrillo al que... a la bestia que siga. Es de él no más, pu(es).

Si el potrillo no seguía a la yegua, sino al caballo.

Ya. Y la señora estaba escuchando eso pu(es): que el rey estaba haciendo una cosa injusta. Y se fueron los otros: el dueño del caballo con su potrillo; y la yegua no llevaba na(d)a pu(es). Así que cuando la señora llama al dueño de la yegua:

-Vuelva, vuelva.

$\mathrm{Y}$ el rey ya se había ido a tender en un living ${ }^{16}$, ahí. Y ella conversó con el hombre, el dueño del potrillo. Así que le dijo:

-Mira, mañana a las once pasa el rey en tal parte. Y ése es un "piedreal" ${ }^{17}$ ahí. Y te tuestas unos dos quilos de maíz. Y te llevas un gualato ${ }^{18}$ y comienzas a sembrar esa hora del... que va a pasar el rey ahí, como a las once. Y el te va a preguntar: "- ¿Y qué estás haciendo ahí, hombre?". "-(Es)toy sembrando maíz tostado, mi rey". Entonces te va a decir él: "—¿Y qué se te va a dar el maíz tostado, hombre, ahí, en ese "piedreal"?" Entonces le dices tú: “-Hoy día están muy cambiadas las cosas del mundo. Fíjese que hoy día no paren las yeguas, sino paren los caballos. ¿Y no se me va a dar el maíz tostado aquí?"

Así lo hizo. Así que entonces (cuando el rey recibió esta respuesta) es que dijo:

- ¡Ah! ésta no más es la que le dijo al caballero, éste.

Dio un palmazo y se fue pa(ra) la casa:

-Mira, ¿no es cierto? -que le dijo-, ¿no te dije que nunca te metas en cosas que no te importen?

-Sí, pero eso era injusto, pu(es) hombre. ¡Cómo se te ocurre que vas... ahora se te va antojar parir, tú! ¡No puede ser, pu(es)!

-El compromiso, o sea el contrato - le dijo-, fue así ¿no es cierto?: que si tú te metías en cosas que no te importen, "los" separábamos.

15 civil : forma elíptica de 'oficial del Registro Civil'.

16 living: 'sala de estar', voz del inglés.

17 "piedreal": variante popular de pedregal.

18 gualato: 'herramienta de labranza similar a un azadón, pero terminado en punta y con una hachuela en su parte posterior'; según R. LENZ, es voz mapuche de Chiloé (DICC. ETIM., s.v. bualato). 
- iJusto, pu(es)! (Es)tá bien.

-Bueno. Lleva tú, hija, to(d)o lo que tú más estimes de aquí.

Bien. Tomó un cuchillo grande que había. Y el rey estaba por allá, así, echado p(ara) atrás:

-(Es)tá muy bien.

Comenzó a arreglarse un cuchillo.

- ¿Y ésta qué irá a hacer? - decía el rey.

Y se comienza a pasear. Y unas vueltas, unas vueltas por allá. Y de un repente ${ }^{19}$ se le tira al salto... al marrueco ${ }^{20}$. Se lo... se lo pescó bien, pu(es).

- ¿Y qué haces, hija?

-No, esto es lo que más estimo. Tengo que llevarlo.

Así que:

-No, hija, no te vayas na(da) -le dijo.

$\mathrm{Y}$ ahí se terminó, señor.

\section{LA ADIVINANZA DEL TAHÚR}

Narradora: Olga Rodríguez Rodríguez (75 años)

Localidad: Casa de Lata (comuna de Río Negro).

Le gustaba jugar al naipe y nunca ganaba; siempre perdía. Después, cuando se halló perdi(d)o, entonces mandó al mozo. Entonces le dijo al mozo:

- Vas a ir a venderme esto.

$\mathrm{Pa}$ (ra) que los otros no sepan qué iba a mandar a vender, entonces le dijo, al mozo:

-El entrepiernas - le dijo- por cincuenta; el mete que saca, por cuatro; y el dale que dale, por tres.

El entrepiernas era el caballo; el mete que saca era el freno; y dale que dale, las espuelas.

\section{LOS NOVIOS QUE NO SABÍAN SU NOMBRE}

Narrador: Segundo Alvarado Barriga (68 años)

Localidad: Las Cascadas (comuna de Puerto Octay).

Bueno. Éstos eran dos jóvenes que estaban de novios, pero ninguno de los dos se conocían, no se sabían el nombre. Entonces un día es que el joven le dijo a la señorita, que le dijo:

-Bueno, yo no te sé el nombre ni tú me sabes el nombre.

Entonces la señorita le dijo:

-Mañana vas temprano a mi... a mi casa y en la ventana, afuera en la ventana, vas a encontrar mi nombre.

Y él es que le dijo:

—Ya, mi nombre es... está en el "Creo en Dios padre".

19 de un repente: variante popular del adverbio de repente.

20 marrueco: 'bragueta'. 
Entonces que... la señorita que dijo:

- "Creo en Dios padre" —empezó a estudiar en la noche-; "Creo en Dios padre" no se llama na(da) éste; "Todopoderoso" menos; "Creador de la tierra" menos.

Y lo estudió: que se llama Ignacio.

- "Y nació" —es que dijo_-, Ignacio se llama éste.

Y él no lo podía estudiar, porque ella estudió en la noche el nombre de él. Y él no pudo estudiar nada en la noche, porque tenía que ir en la mañana a encontrar el nombre de ella en la ventana de su casa, pu(es). Entonces es que dijo:

-iPucha! ${ }^{21}$

Se fue en la mañana, temprano, y llega a la ventana donde tenía su pieza su novia. Y afuera ve una tina. Y adentro de la tina había una flor. Quedó pensando, es que dijo:

-Aquí tiene que estar el nombre de ella, pu(es).

Entonces es que dijo:

- Tina no se puede llamar ésta; Flor, tampoco.

Y la empezó a estudiar. Y ahí es que dijo:

-Flor-en-tina. Se llama Florentina.

Porque la flor estaba en la tina. Así que es que dijo:

-Tiene que llamarse Florentina.

Entonces se levantó la señorita y se encontró con él afuera:

- Muy buenos... buenos días, señor Ignacio.

-Buenos días, señorita Florentina -es que le dijo.

¡Ja, ja! Se adivinaron el nombre, pu(es). Y de ahí... ahí se casaron después, porque tenían que adivinarse el nombre pa(ra) que se casen ${ }^{22}$.

Y hasta ahí no más.

\section{EL HIJO QUE SE ENAMORÓ DE SU MADRE}

Narrador: Segundo Alvarado Barriga (68 años)

Localidad: Las Cascadas (comuna de Puerto Octay).

Ésta era una señora que vivía con un hijo no más. Y el hijo se enamoró de la mamá. Entonces un día se declaró el hijo adonde... a la mamá, pu(es). Entonces la mamá es que dijo:

-No puede ser eso, pu(es). ¿Sabe qué, hijo? —es que le dijo-. Yo te voy a dar un retrato y búscate una mujer al retrato mío, pu(es) ${ }^{23}$. Y te voy a dar plata ${ }^{24}$.

21 ipucha(s)!: expresión eufemística de disconformidad, desconcierto, por iputa! (cfr. Ambrosio Rabanales, Introducción al estudio del español de Chile. Determinación del concepto de chilenismo, Anexo núm. 1 del Boletín de Filología de la Universidad de Chile, Santiago de Chile: Editorial Universitaria, 1953, p. 112).

22 Discordancia bastante frecuente: pretérito de indicativo en la oración subordinante y presente de subjuntivo en la oración subordinada. Cfr. Constantino ConTreras, "El castellano rural de Osorno (a través de textos orales)", en Estudios Filológicos, núm. 28, Valdivia, Universidad Austral de Chile, 1993, pp. 123-135; vid. p. 128.

23 Se entiende que en esta oración está elíptico el adjetivo parecida, más cuando dicha palabra aparece expresa más adelante en un contexto similar (en el tercer párrafo). 
Y corre... corre por to(d)o el mundo si (a)caso no... hasta donde encuentres una persona, una mujer al retrato que te voy a dar.

Claro, entonces el joven tomó el retrato y su mamá le dio plata y salió. Ése anduvo por todas partes. Nada que podía encontrar una mujer parecida al retrato.

Y de ahí se juntó con unos amigos un día: que le(s) conversó la historia. Que le dijo... que le dijeron los amigos:

- ¿Sabes qué? ¿Adónde puedes encontrar mujer a ese carácter del retrato? En la misa, porque ahí llegan muchas mujeres y ahí puedes encontrar la mujer que buscas.

Así que se fue, se fue a la misa, a un pueblo. Entonces se quedó en la "dentrá" 25 de la puerta de la iglesia, mirando las personas y mirando el... el retrato que andaba tra(y)endo, pu(es). Entonces... nada más, ninguna es que. Al final, llega un coche, con una señorita. Se desmontó la señorita y pasó pa(ra) dentro, pa(ra) la misa.

Sacó la fotografía ahí. Era la misma. Entonces él es que le dijo:

—iAy, señorita —es que le dijo—, quién... quién pudiera saberle su nombre! Entonces la señorita se dio vuelta, que le dijo:

- Si el e... si el e-na-mo-ra-do

fuera bien fijado

$y$ de buen sentido, aquí le dejo mi nombre del color de mi vestido.

Entonces es que quedó pensando:

- Si el enamorado fuera bien fijado y de buen sentido, aquí le dejo el nombre... de mi vestido.

Y ella andaba con un traje morado. Entonces es que quedó pensando él, es que dijo:

- ¿Cómo se llama ésta? El enamorado... Ella.

Lo sacó luego, es que dijo:

-El e-na-morado. Se llama Elena Mo... mo-ra-do... Mora, Elena Mora.

Y se le salió que... después cuando salió de vuelta es que le dijo:

- Señorita Elena Mora, usted va a ser mi esposa.

Y... y se casaron, pu(es).

Y hasta ahí. Ahí terminó el cuento.

\section{EL REY QUE TENÍA TRES HIJAS CASADERAS}

Narradora: Pilar Silva Flores (83 años)

Localidad: Entre Lagos (comuna de Entre Lagos).

Un rey tenía tres hijas y no hallaba con quién hacerlas casar. Entonces él que dijo un día:

— ¡Bah! —es que dijo- ¿De a(d)ónde me salió (bueno, la palabra es...) un piojo? (Un piojo) se halló él en el cuerpo.

24 plata: 'dinero' (DHCH, p. 181).

25 "dentrá": variante de entrada. Cfr. la conservación del antiguo verbo dentrar (entrar) "con gran persistencia en la lengua popular", según R. OROZ, op. cit., p. 343. 
- ¡Oh, este piojo!, lo voy a mandar a criar.

Se lo dio a otro, a un viejito, por ahí.

Ya (es)taba de más grande es que, el piojo. ¿Crecerá? ¿Quién sabe cómo será, $\operatorname{pu}(\mathrm{es})$ ?

Ya, que dijo:

- Mire, patrón —es que le dijo-, le entrego —es que le dijo- su animal. Ya está muy grande.

Bueno. Tenía un viejito. Ése lo mató. Y que le estaque el cuero. El cuero del piojo iba a estaca(r)lo ${ }^{26}$.

- iAhora, a saca(r)le ese cuero a ese piojo!

¿Cómo sería ese cuero de ese piojo?, digo yo. Jue...! ¡Colga(d)o!

Es que dijo ahora:

-Aquí va a ser la suerte de mis hijas. Quien me adivine qué... de qué animal es este cuero, se casa con una de ellas.

Ya. ¡Fu!, gente había: venían alemanes, venían de todas partes, "nadien" ${ }^{27}$ adivinó, no, no, "nadien" adivinaba qué... qué... de qué va a ser este cuero. No, pu(es).

Él tampoco decía. A las perdidas ${ }^{28}$ es que dijo...(bueno, es que dijo). Éste se olvidaría, pu(es). Le dijo a su mozo:

- Oye -es que le dijo-, ven pa(ra) acá!

- ¿Pa(ra) qué?

Se fue.

- ¿Tú adivinas —es que le dijo- de qué es ese cuerecito que hay ahî?

Él que le dijo:

-Ése... el cuerecito ese es de un piojo.

¡Claro! Ése adivinó. Claro.

-Entonces tú te casas con mi hija —es que le dijo.

¡Ya está! Y se casó la hija con el viejito. Se casó la hija, por hacerle el gusto a su padre, se casó la "príncipa" ${ }^{29}$ con el viejito, un mozo.

Entonces es que dijo la niña, le dijo a él:

- "Los" ${ }^{30}$ vamos, lejos, a trabajar. Yo no estoy aquí.

Y se fueron. Tenían que pasar un río. El viejito no podía pasar. Ya ella lo pasó. ¡Póngale caminar! Por ahí pasaron otros. Serían esteros que pasaban. ¡Quizás cómo sería! Ya por ahí lo echó "a chique" ${ }^{31}$. Se aburrió la niña. Y de ahí es que dijo:

26 estacar. 'sujetar, clavar con estacas', especialmente "cuando se extienden los cueros en el suelo para que se sequen" (DHCH, p. 111). En el nivel sintáctico, nótese la anteposición del complemento directo, como si se tratara del sujeto, y su reiteración mediante el complementario lo.

27 "nadien": variante popular del pronombre indefinido nadie, con intención pluralizadora (cfr. R. OROz, op. cit., p. 299).

28 a las perdidas: loc. adv. que equivale a 'repentinamente', 'al azar'.

29 "príncipa": forma fem. creada por contraste con príncipe y equivalente a 'princesa'.

30 Cfr. cuento núm. 2, nota 12.

31 a chique: loc. familiar equivalente a 'a cuestas'. R. LENZ registra hacer cheque a alguien = 'llevarlo a la espalda', del mapuche chiquin 'cargar a las espaldas como a los 
- Voy a echar al agua a este viejo, mejor.

Y al otro que pasó, lo llevaba "a chique", de repente es que le dijo:

- ¡Ay!, casi me caí.

El viejo ese se largó al agua. Se lo llevó el agua. Ella no lo hizo caso. Se fue no más. Ella se fue sola, andando.

Mucho había anda(d)o. La encontró un... un príncipe, de a caballo. Andaba viendo sus animales.

— ¿P(ara d)ónde va, señorita?

- Voy -es que le dijo- por ahí -es que le dijo- a buscar trabajo.

- iAh! Vamos pa(ra) mi casa.

- Vamos.

Se fueron andando, conversando. Y era... llegó a la casa. Y es que le dijo:

-Esta niña —es que le dijo- venía caminando —es que le dijo- por ahí y yo la traje - a su mamá.

Y ella es que le dijo:

-Bueno -es que le dijo.

Y ahí... ya quedó ahí la niña. Un día es que dijo:

-Bueno, voy a salir -es que dijo- a buscar trabajo.

Salió. Se fue a buscar trabajo a(d)onde dos viejitas que "habían". Esas dos viejitas tenían unos...(bueno, ¡quién sabe cómo sería, pu(es), eso!) le decían que eran... una sapita (¿de esas ranas serán pu(es)?). Esas tenían engorda(d)as que hacían unas... Ella le iba a dar qué comer: comía. Bueno, la sapita gritaba ahí.

Ya. Un día vino un joven y le dijo:

- ¿Qué estás cuidando ahí?

-Estoy cuidando —es que le dijo- estos animalitos aquí.

—Bah! —es que le dijo- ¡Estas viejitas tienen esto —es que le dijo- aquí guarda(d)o!

— ¿Seguro? —es que le dijo ella-. ¿Cómo será?

-Así es -que le dijo-. ¿Y por qué no se va $\mathrm{p}$ (ara) mi casa usted?

-No —es que le dijo ella-. ¿Quién sabe a(d)ónde será?

-Allá, en tal parte es mi casa -es que le dijo.

- ¿Qué está haciendo aquí usted?

-Bueno - es que le dijo la niña-, me voy; si hay trabajo allá, voy.

Se fue. Quedó el servicio pa(ra) cuidar los sapitos. Entonces este joven lo que hizo: llegó y no le quiso decir a su "mami" ${ }^{32}$ que llevaba esa niña y la... la encerró, en su pieza. Ahí quedó la niña encerra(d)a. Que viva ahí él le llevaba qué comer, le llevaba de todo.

Y ella es que dijo. Bueno, de tanto ya la señora es que dijo:

-Bueno, ey éste qué... qué tendrá encerra(d)o ahí que no puede abrir esa puerta? No quiere que nadie se la abra. ¿Y ahora la ropa?

Llegó el joven en la tarde. Ella es que le dijo:

-Oye -es que le dijo-, dame tu ropa pa(ra) lava(r)la —es que le dijo.

-No —es que le dijo él-, yo se la voy a dar mañana.

- ¿Y por qué no puedes abrir la puerta?

chiquillos' (DICC. ETIM., p. 272). En el español de Chile hay otras expresiones sinónimas: al apa y al acba (cfr. DHCH, pp. 37 y 50).

32 "mami": forma afectiva familiar para dirigirse a la 'madre', por apócope del diminutivo mamita. 
-Porque no -es que le dijo.

-Y... yo —es que le dijo- parece que veo —es que le dijo- que algo tenís ${ }^{33}$ encerra(d)o.

Y ya la viejita se enojó por ahí.

Y de ahí es que le dijo él:

-Bueno -es que le dijo-, ¿tan enoja(d)a?

Abrió la puerta: ¡una "príncipa"!

$Y$ es que le dijo:

- Y tenías esta niña muriendo aquí —es que le dijo.

-No - es que le dijo-, si... yo me voy a casar con ella.

- Bueno - es que le dijo-, se casa, pero que... tiene que la niña salir.

Ya, enoja(d)a la viejita. Se iba a casar el rey con la niña.

Ya la niña quedó en la casa. Y es que dijo un día... ¡Ah!, vino una de esas negras a alquilarse pa(ra) cocinera. Entonces es que le dijeron:

-Bueno.

Ya "se emplegó" ${ }^{34}$ con la señora, la negra. Y por ahí la negra ya pri(n)cipió a... (quería ella casarse con el príncipe)... a interesar al patrón. Y... que le gustaba el patrón, ella se iba a casar. Ella no halló cómo que pueda matar la niña, la negra ${ }^{35}$. Un día es que le dijo:

-iMira —es que le dijo-, qué bonitos anillos tiene uste(d)!

- Sí —es que le dijo ella-. Esos anillos los tengo —es que le dijo-...recuerdos de mi casa.

- iAh! —es que le dijo- y yo tengo —es que le dijo- unos anillos bonitos también.

Se sacó el anillo la negra y se lo puso a la niña, aquí. Murió la niña. Ya está. Se quedó muerta la niña en la casa. Ya está. Llegó la viejita. ¡Uh! la armonía porque se había muerto.

- ¿De qué murió?

-iQuién sabe!

Llegó el príncipe: muerta su niña. Ya está, pu(es).

-Ahora ¿qué vamos hacer? Hay que vela(r)la ¿Cómo es esto?

-Pero —es que decía la... la negra-, pero si ésta no está hela(d)a, pu(es). Ésta parece que estuviera durmiendo.

¿Ah? Bueno. Así que el príncipe, enoja(d)o, entonces es que dijo:

- ¿O esta negra algo le hizo?

Pri(n)cipió es que a buscarle. Desconoció el anillo. Que le dijo:

— ¿Y el anillo que tenía? - -es que le dijo-... No lo tiene. ¿A(d)ónde está? Y ésta tiene otro.

Fueron. Le sacó el anillo: ¡vivió la niña!

— ¿No ves? —que le dijo-, que este anillo que tenía la negra... ¡A mata(r)la! ¡Ahora a mata(r)la!

33 tenis: forma verbal voseante, es decir, equivalente a tenéis (de la 2.a pers. de pl.) y empleada para la $2 .^{a}$ pers. de sing.

34 "se emplegó": 'encontró empleo'; nótese la intercalación de -g-por ultracorrección.

35 Nótese la ausencia de preposición a en complemento directo personal, posiblemente conservación de un uso antiguo. Cfr. C. ConTrERAS, art. cit., p. 131. 
Entonces, por la picardía de la negra, fue y fue a traer unos caballos, la amarró a la cola, la mató a la negra ${ }^{36}$. Se fue la negra. La hizo pedazos. Murió la negra. Y él se casó con la... con su "príncipa" otra vez.

\section{EL REY QUE TENÍA UN CAJÓN DE PLATA}

Narrador: José Segundo Arcos Paredes (76 años)

Localidad: Huali (comuna de San Juan de la Costa).

El rey es que tenía un cajón de plata y se le perdió. Se le perdió un cajón de plata y oro que tenía. Antes sellaban oro y plata. Entonces, cuando se perdió el cajón de plata, éste los mandó presos a los dos pu(es), "habían" ${ }^{37}$ dos mozos. Y los mozos no más tenían que haber sido: de haber sacado las cosas de adentro de la casa.

-Bueno - es que les dijo-, si no aparecen, yo los voy a... los voy a matar - les dijo-. Les voy a dar tres días de plazo.

Entonces los mandó a dar de comer (a un adivino que estaba preso y que tenía tres días de plazo para descubrir dónde estaba el tesoro).

Primer día:

- Gracias a Dios, ya va uno -dijo.

Después, al otro día, le fueron a dar de comer otra vez:

- Gracias a Dios que van dos-dijo.

$Y$ entonces, al tercero día ${ }^{38}$ dijo uno de ellos:

-Oye, si acaso... mejor declarémosle —dijo- a éste. Declarémosle adónde "tenimos" 39 la plata.

Y el rey tenía preso al adivino. Era un adivino de profesión, de allá. Entonces ese adivino estaba preso. Y los mozos le iban a dar de comer. Entonces dijo, para que el rey no los mate después:

- Bueno - les dijo-, yo les voy a gratificar esto a ustedes - les dijo, y queyo los voy a salvar. Me dicen (d)ónde la tienen no más.

- "Tenimo(s)" la plata enterra(d)a —dijo- lejos pa(ra) allá (d)onde hay un tronco de árbol, ahí.

Entonces le(s) dijo:

-Ustedes van a ir. Vas a ir adelante tú -le dijo a uno-. Y me vas a hacer una seña con el taco del zapato: una cruz ahí, (d)onde está la plata, el dinero enterrado. Entonces yo voy a ir más atrás.

Porque lo llevaban preso al adivino de profesión ${ }^{40}$, pu(es). Así que llegó entonces, pasó el mozo, y vio, hizo la cruz ahí, que "nadien" ${ }^{41}$ se dio cuenta. Y siguió adelante. El mozo adelante. Donde hizo la cruz, ahí:

36 Cfr. esta clase de construcción con la señalada en el cuento núm. 6, nota 26. Sobre duplicación del objeto directo, cfr. C. CONTRERAS, art. cit., p. 127.

37 Como en otras ocasiones, se pluraliza la forma impersonal de haber.

38 El narrador no apocopa el numeral ordinal tercero (tercer) ante el sustantivo.

39 "tenimos": El cambio desinencial -emos > -imos revela el uso de una forma de $1 .^{a}$ pers. pl. de un verbo de la $2 .^{a}$ conjugación como si fuera de la $3 .^{a} \mathrm{R}$. OrOz anota precisamente que "la confusión de dichas formas se observa con más frecuencia en las zonas rurales sureñas" ( $o p$. cit., p. 308). Se corrobora en C. CONTRERAS, art. cit., p. 127.

40 Expresión del objeto directo a través del complementario y del complemento. Cfr. cuento núm. 6, nota 26.

41 "nadien": cfr. cuento núm. 6, nota 27. 
-¡Deténganse! -dijo.

Andaba con un bastón y lo sondeaba.

- Por aquí cerca está -dijo-. ¿A ver? Claro, aquí está, tierra removida, aquí tiene que estar esto - dijo.

Ya, empezaron a cavar, cuando de repente salió un grillo. Y se llamaba Grillo, el apellido de éste... Ahora... el grillo lo tomó, el rey lo tomó y lo escondió.

-Adivina - dijo- ¿qué es lo que tengo en el pañuelo? - le dijo el rey.

-iAy! —dijo-, voy saliendo de una —dijo el adivino de profesión-y ahora me metí a otra - dijo-. ¡En qué apretura te ves Juan Grillo! —dijo él.

Se llamaba Grillo de apellido.

- iGrillo era pues hombre! ¡Me adivinaste! - le dijo. Je, je!

Soltó el grillo. Así es que fueron. Ahí estaba el cajón con plata, enterra(d)o. ¡Contento el rey!

Así que... y (el adivino) tenía un rótulo que decía "Adivino de profesión", pu(es). Y ese día cuando ya se salvó ¡abajo rótulo, señores! Le pagaron y partió pa(ra) otra parte.

-De otra vez no me escapo - dijo.

8. GRILlO, El ADIVINO DEL REY (cfr. con el cuento núm. 7)

Narrador: Juan Eduardo Fuentealba Bahamonde (68 años)

Localidad: Trumao (comuna de San Pablo).

Es que el rey tenía dos esto..., no, tres criados. Era un rey que tenía tres criados. Entonces éstos le... le hicieron un robo al rey. Y entonces el rey dijo, pu(es):

- ¿Qué se me habrá hecho? Tanto, tanto dinero que se me perdió y no supe, no he sabido y ni puedo saber quién lo puede tener o cómo se me ha perdido, cómo se me desapareció esto.

Entonces hizo buscar un adivino que había, ¿m?, a un anciano adivino. "Jueron" ${ }^{42}$ a buscar el adivino. Y le dijo:

- Señor rey -le dijo-, usted me ha mandado a llamar.

- Sí - le dijo-, porque se me perdió dinero aquí y no sé qué lo que se ha hecho. Nada menos que son como tres sacos de dinero-que le dijo-y usted me va a adivinar. Y tiene plazo tres días; tiene plazo tres días para decirme; si no, la cabeza se le va a cortar - le dijo y lo encerró en una pieza.

Va el rey y ordena a sus criados. Dijo:

-Tú le vas a llevar la comi(d)a a éste - al anciano.

Le llevó al otro día. Ya lo encerraron al anciano ${ }^{43}$. Y al otro día le llevó..., el primer criado, ése le llevó el... el desayuno. To(do) el día le acarreó en ese día. Le llevó el desayuno que el rey dijo.

Le recibió el desayuno el anciano. Es que le dijo:

- ¡Gracias a Dios que tengo uno! - im? - ¡Gracias a Dios que tengo uno!

Tenía un día ya, pu(es). Y eran tres días es que.

42 La alternancia de los fonemas fricativos /f/ - / x/, según $\mathrm{R}$. OROz, "es muy común en la lengua popular de nuestro país", con excepción del extremo norte (op. cit., p. 167).

43 Cfr. cuento núm. 7, nota 40. 
Ya él "se jue". "Se jue". Él le dijo, el otro criado le pregunta:

- ¿Qué te dijo el anciano?

-Dijo: "Gracias a Dios" cuando recibió el desayuno. Me dijo: "Gracias a Dios que tengo uno".

¡Pucha! ${ }^{44}$-dijo-, ya está adivinando este jodido ${ }^{45}$, ya pu(es) —es que le dijo-. Mañana voy a ir yo. Espérate no más, a ver qué dice.

Y al otro día le tocó al otro, pu(e)s, a dejarle el desayuno. De nuevamente ${ }^{46}$ tocaron la puerta y le dijo:

- Vengo a dejarle el desayuno, señor.

El anciano recibió el desayuno. Harto triste es que le dijo... dijo:

- iGracias a Dios que tengo dos!

Ya se quedó triste el... el sirviente. Y "se jue" pa(ra) donde... pa(ra) la cocina. Le preguntó el último. Que le dijo:

- Mira -es que le dijo-, ¿qué dice el anciano?

-Al "recebir" el desayuno dijo lo mismo, p(ues) hombre -le dijo-: "Gracias a Dios que tengo dos”. ¡Pucha! ${ }^{47}$, ya van faltando... Éste está adivinando, este jodido.

-Deja, mañana voy a ir yo —es que dijo el último.

-Bueno - es que le dijo.

Al otro día "jue" pu(es). En la mañana otra vez tocó la puerta. Es que le dijo: -Aquí está el desayuno, señor.

Salió el ancianito, bien triste. Le dijo..., le recibió el desayuno y que le dijo: - iGracias a Dios que tengo tres!... que tengo los tres.

- iPucha! —es que le dijo-. Mire, viejito —es que le dijo-, usted ya adivinó - y eran ellos los que habían robado la plata, pu(es)_. Usted adivinó. Nosotros fuimos los tres que robamos la plata -es que le dijo-. Mire -es que le dijo-, adivine no más, pero no "los" 48 eche al... al agua a nosotros.

- Sí —es que le dijo-, si yo sé que ustedes "jueron". Ya, claro, ustedes fueron.

Bueno, y "agora" ${ }^{49}$ es que le dijo:

- Mire —es que le dijo-, adivine no más.

-Dime bien a(d)ónde tienen la plata, porque ustedes "jueron".

- Sí —es que le dijo-. Mire —es que le dijo-, hay... hay tres palos en tal parte -es que le dijo-, tres troncos, y ahí están los tres sacos de plata enterrados, enterrados —es que le dijo-; y ahí van y escarbe; de lejos se ve —es que le dijo-; y ahí están; pero no diga que fuimos nosotros.

Entonces es que le dijo él:

-Bueno, los voy a salvar —es que le dijo el viejito.

$\mathrm{Y}$, bueno, "se jue".

44 Cfr. cuento núm. 4, nota 21.

45 jodido: 'enfadoso, importuno, majadero', acepción frecuente en el habla popular (cfr. $\mathrm{DHCH}$, p. 128). En el contexto tiene el sentido de 'difícil de engañar'. Más adelante, la expresión "Estábamos jodidos" adquiere el valor de 'estábamos frustrados'.

46 de nuevamente. cruce entre las formas adverbiales nuevamente y de nuevo.

47 Cfr. cuento núm. 4, nota 21.

48 Cfr. cuento núm. 2, nota 12.

49 "agora": forma anticuada del adv. ahora (R. OROz, op. cit, p. 32). 
- QQué te dijo? -es que le dijo el otro, uno es que le dijo- ¿Qué?

-Lo que dijo: "Gracias a Dios que tengo los tres". Estábamos jodidos, pero ya quedó todo arreglado, hombre -es que le dijo-, porque el viejito dice que no nos echa al agua a nosotros, im?, no nos echa al agua a nosotros.

Y en esa conversación (es)taban. No los escuchó el rey, sino es que... que les dijo:

- "Vaigan" "s a buscarme el anciano!, para que me diga. Ya éste adivinó, porque hoy ya tenía plazo tres días.

- ¿Qué tal, buen viejo? -es que le dijo, cuando lo... cuando llegó ya a la presencia del rey, es que le dijo- Bueno, ¿adivinaste?

Sí -es que le dijo.

-iQuién "jue"? ¿A(d)ónde está el dinero?

-En tal parte está —es que le dijo.

Y no le preguntó el rey nada quién "jue", sino es que le dijo:

- iAld)ónde está el dinero?

-En tal parte está. Es que así fue la condición, señor rey.

$Y$ ahi le dijo él:

-Bueno —s que le dijo-, vamo(s) a busca(r)lo. Vamos a ver.

- Aqui es -que le dijo.

Ellos llegaron a los... a los palos, ahí (d)onde le ${ }^{51}$ había dicho el criado.

I.e (lijo:

-Bueno - ess que le dijo-, escarben aquí, pu(e)s. Aquí tienen; aquí están.

Y el... escarbaron un poco; luego es que ya hallaron un... van hallando un saco; ya hallaron el otro; y faltaba uno.

- A ver -es que le dijo-, más acá. a un lado; ahí tiene que estar el otro. Y ahí éstá.

Y ahí estaban, pu(es).

El... el rey mira pa(ra) un lado es que, o sea el viejito mira pa(ra) un lado. Salta un grillo; va el rey y se lo pesca. Sacaron el... sacaron la ... plata.

Le dijo:

-Bueno -es que le dijo-, has adivinado, hombre. Adivina -es que le dijo-, buen advinador-, qué tengo en la mano.

- iAy! -es que dijo- ¡En qué apretura te hallas, pobre Grillo!

-icirillo es, prues) hombre! -es que le dijo.

Y el... el adivino se llamaba Grillo.

Alú termino.

\section{9) (ITNTO (ON ADIVINANZA}

Narradora: Fimilia Garcés Pérez ( 78 años)

Localidad: Cancura (comuna de Osorno).

Eran tres hermanas, pu(es). Y un rey tenía tres hijos. Y los príncipes interesa(d)os pa(ra) casarse con una de ellas, pu(es). Asi que entonces uno de los hermanos, el

* "vaigan": variante popular de tayan (cfr. R. OROz, op. cit. p. 339).

" le El uso del dativo le para el plural, en vez de les. puede deberse a la elisión le la aspirada resultante de -s implosiva. No es fenómeno sólo del español de Chile (cfr. R. OROZ, op. cit., p. 376). 
mayor, el leso ${ }^{52}$, todos los días iba a ver. Al fin el rey alcanzó a saber y es que ahí dijo:

-Bueno - que dijo el rey-, jesto no lo voy hacer acabar con las adivinanzas!

Una adivinanza que sacó. No sé cómo era la adivinanza que tenía él. iQuién le adivinaba la adivinanza al rey!

¡Ah!, cuando decía el rey: "¡Hay una adivinanza —que les decía-, porque hicieron un fora(d)o 53 !". Éste era el rey príncipe, vivía arriba. Asi que este príncipe era solo... Así que había un viejito. Tenía una hija. Y la hija iba, entonces la hija entró por un fora(d)o que hizo, entró arriba (d)onde vivía el príncipe. Y así que entonces esta niña se sintió gorda ${ }^{54}$ del príncipe. Tuvo su guagüita ${ }^{55}$. Cuando tuvo su guagüita ¿qué hizo?: que arregló un canasto largo. Así que cuando arregló el canasto largo puso la guagüita en el canasto y puso hartas flores. Y para ofrecerlas había que "dicir" 56: "iQuién compra flores, mal de amores!".

Entonces le dijo ella a su papá ${ }^{5}$ :

-Papá - le dijo-, vas a ir a vender estas flores (d)onde el príncipe.

- iAy, hijita! - le dijo- ¿cómo voy a ir?

- Sí - le dijo-, bien arregla(d)o.

Arregló la guagüita al medio, bien tapa(d)a. Y las flores encima.

Y llegó al rey. flores...!"

— "iQuién compra flores, mal de amores!” —es que decía él- "iQuién compra

Y ahí es que dijo un portero, el guardián en la entra(d)a del príncipe.

$\mathrm{Y}$ el negro (el portero):

-Oye —es que le dijo-, ¿vendes "flores, mal de amores"? Voy a decirle al patrón.

—Patrón!, ipatrón! —que le dijo-, un viejito anda vendiendo "flores, mal de amores".

-iAh, hijito!, dile que pase p(ara) acá.

Subieron $p($ ara $)$ arriba con el canasto. Fl viejito... y deja el canasto ahí, a boca de jarro. Porque ella le dijo:

- Cuando le pida el canasto, papá - le dijo-, el principe, arriba, deje el canasto y salga al tiro ${ }^{5 *}$. No espere nalda) canasto.

Y salió el viejito.

Cuando él vio el canasto, vio a su guagua. Conoció a la guagua.

- iAhora! —es que dijo-, jahora va a ser pu(es)!... ¡Qué! —es que dijo él-. de alguna manera tengo que dar con ella.

Así que conoció a la guagüita, llamó a sus emplea(d)as: que crien la guagüita, que le lleven la guagüita. Fue hombrecito, así que crien su guagüita.

5: eso: 'tonto, necio, de inteligencia muy limitada', acepción corriente en Chile (y países vecinos, según el DHCH, p. 132).

53 forado: 'horado hecho en una pared o techo' (DHCH, p. 113).

54 gorda: nombre dado vulgarmente a una 'mujer embarazada' (DHCH, p. 117).

5 Cfr. cuento núm. 1, nota 1.

to "dicir": variante de decir, por asimilación vocálıca.

5- Uso de le 'redundante' para anticipar un complemento indirecto (cfr. R. ORoz, op. cit., p. 376).

is al tiro: loc. adv. equivalente a 'en seguida, inmediatamente' (cfr. DHCH, p. 225) 
Ahí dicen que sacó una adivinanza el rey y dijo que el príncipe se casaría con la hija de aquél que le adivine ${ }^{59}$ la adivinanza. Así que de ahí... entonces el rico, arriba en el solio, es que dijo:

- Estaba el palomo un día

arriba en el palomar;

vino la paloma,

lo vino a tantear.

No "lo" vieron salir

ni menos "dentrar" 60 .

Ésa era la adivinanza, pu(es). Bueno ¡Uh!, to(d)itos se iban a amontonar, pu(es) ellos, tord os los ricos, tantos.

-iQuién adivina? ¿A ver? ¡Arriba! —es que "dicía" él.

Tres veces "dicía":

-Estaba el palomo un día

arriba en el palomar;

y vino la paloma,

lo vino a tantear.

No "lo" vieron salir

ni menos "dentrar".

¡Todos mudos!... Bueno, ya le dijo:

- Papá - le dijo su hija- (eran tres días no más), papá -le dijo-, cuando diga la adivinanza ese rey, usted contéstele. Sígale - le dijo-: "Lo que llevó, lo mandó a dejar".

Ése era el contenido: que ésa era la guagua.

Cuando dijo el rey, arriba, detrás dijo (estaban amontonados los ricos), si que dijo el rey:

-Estaba el palomo un día

arriba en el palomar;

vino la paloma,

lo vino a tantear.

No "lo" vieron salir

ni menos "dentrar".

- "Lo que llevó, lo mandó a dejar" -le dijo.

$Y$ se fue el viejo, corriendo.

- Cárguenle el viejito" (es que "dicían".

Le cargaron pu(es). Lo llevaron a una casita chica "2. Ahí estaba el viejito.

la le fueron a "dicir" al príncipe. Le dijo:

En una casa chiquita vive - le dijo- con su hija.

- ¡Dile que venga!

-Los otros ya se fueron.

- iDile que venga! ¡Traigan al viejito!

Llegó el viejito. Llegó arriba (d)onde estaba el... el príncipe.

50 Cfr. cuento num. 2. nota 0 .

(w) Observese el uso de la forma acusativa lo para un referente femenino; y el empleo de la variante verbal dentrar (entrar). Cfr. cuento núm. 5, nota 25.

"1 ¡Cárguenle el viejito! = 'Alcancen al viejito!"

0. casita chica: reforzamiento de la forma diminutiva. 
Entonces es que le dijo:

-Mire, mi buen anciano -le dijo-, ¿usted tiene una hija?

-Sí.

- ¿Y tuvo una guagüita?

- Sí.

- ¿Y la guagüita?

— "Lo" vine a dejar, pu(es) — le dijo. Y la guagüita le vine a dejar a usted.

Entonces le dijo:

-Entonces yo me voy a casar con su hija. La trae.

- iEs posible! —es que le dijo- Nosotros somos pobres -es que le dijo-y usted no se puede casar con mi hija, pu(es).

— ¡No! ¡Yo me caso no más! —es que le dijo-, me caso.

-Bien, se casan.

Llevó a su hija el viejito. ¡Uf!, el viejito quedó como un buen príncipe. Se casó la señorita con el príncipe y crió su hijo ${ }^{63}$. Ése quedó un rico. ¿No ves?

\section{LOS TRES HERMANOS Y LA ADIVINANZA PARA EL REY}

Narrador: Dalmiro Raipán Lleufo (72 años)

Localidad: Moncopulli (comuna de Entre Lagos).

Eran tres hermanos y quisieron salir a correr tierras, por ir a la casa del rey. Y el rey tenía ofrecido: quien le llevara un cuento que él no lo adivinara... que le daba una hija.

Bueno, así que salieron los tres hermanos. Ya pidieron permiso a sus mayores y se fueron: uno cortó por un camino; otro cortó pa(ra) (e)l otro. Y Manuquito ${ }^{64}$, ése era un poco... que parecía que le fallaba ${ }^{65}$ un poco; pero el caso es que no fue así.

Así que la señora dijo, cuando le dio al último... le dio una tortilla y le dio un huevo, envenena(d)o:

- Porque este pobre - dijo- mejor que muera por el camino y ante(s) que lo mate el rey, pu(es). Porque allá quizás qué disparate va a decir y allá va a ser muerto por el rey. Mejor que muera solo.

¡Ya está! Anduvo un buen trecho, de a caballo, con su mulita, con la Marta, pu(es). Por ahí le dio apetito de servirse algo. Así que dijo:

-Este huevo no lo como na(d)a ${ }^{\text {st }}$.

Mejor se lo dio a la Marta:

- Toma, Marta, sírvete este huevo.

La Marta se lo sirvió, pu(es).

Al rato ya comenzó a morir la Marta, pu(es). Super ${ }^{6-}$ veneno, empezó a morir. Murió pu(es). Y él quedó con la montura no más ahí. Ya está. Y quedó observando ahí.

63. Ausencia de la preposición a en complemento directo de persona. Cfr. cuento núm. 6 , nota 35 .

64 Mañuquito: hipocorístico diminutivo de Manuel.

${ }^{65}$ fallarle: expresión elíptica por 'fallar o faltar a alguien la inteligencia'.

66 Obsérvese la duplicación del objeto directo y la duplicación de la negación.

${ }^{67}$ El empleo de super, en este caso como adjetivo, es un inesperado anglicismo en el habla de un campesino; sin embargo, puede ser explicable por el contacto con 
De repente llegaron tres perros, a comerse a la Marta. Los perros no aguantaron na(d)a. La Marta estaba envenena(d)a, pu(es); no aguantaron na(d)a. También se murieron. Los tres perros quedaron de espalda ahí, muertos.

Ya. Al rato llegan siete jotes. A comer la Marta también. También ya murieron los siete jotes.

-Ya está - dijo Mañuco-, aquí tengo la adivinanza, por mis manos: "Uno mató a Marta, Marta mató a tres y tres mataron a siete".

Ahí sacó la adivinanza. Ya está, dejó todo botado ahí y siguió su camino. Y al final llegó (d)onde el rey, que da la prevención de eso. No ve que el rey, cuando quería comer gente, antes, ya comenzaban a hacer cualquier cosa por mandamiento. Y ahí iban ca(y)endo, pu(es). Los iban guardando.

Yá. Llegó y se presentó. Y con el rey ahí. Al otro día en la mañana le contó el cuento... le contó la adivinanza, la adivinanza no más.

Le dijo:

- "Uno mató a Marta, Marta mató a tres y tres mataron a siete". Y adivine, mi Senor Rey.

No hubo (aso. No pudo adivinar el rey. Anduvo. ¡P(or) (d)onde no anduvo! Sus adivinas que tenía: ¿qué lo que contenía? No. Se encerró.

- Palabra de rey no debe faltar —dijo-. Tú te casas con mi hija.

¡Ya está, pu(e)s! Se casó Mañuquito, que lo consideraban leso ${ }^{68}$, que no podía llegar a los suegros. Se casó Mañuquito y iya está!: quedó "mandarún” 69 y salió. Dijo:

-Ahora tengo que ir a mi casa.

Se fue con un coche, hueno y bien chatre; y su señora. Los viejitos se asustaron cuando llegó Mañuco.

- Yo soy Mañuquito. No pensaba nunca...

De ahí, después le siguió el cuento cómo había sido. Su riqueza. Quedó rico también. ¡Ahi tiene usted!

\section{Cuento (omo adivinanza (cfr. con el cuento núm. 10)}

Narrador: Segundo Alvarado Barriga (68 años)

Localidad: Las Cascadas (comuna de Puerto Octay).

Bueno, comienzo desde que el joven salió de su casa para hacerle la adivinanza al rey, para que se case " con la princesa.

Entonces, la mamá le hizo un... una tortilla, una leuca ${ }^{-1}$, y... y le puso veneno pa(ra) que... muera antes que llegue a(d)onde el rey, pues.

escolares, especialmente del medio urbano (tal vez los mismos nietos del narrador), entre quienes si es frecuente

o* leso: cfr. cuento núm. 9, nota 52.

(1) "mandarún": 'mandarín'.

"Cfr. cuento núm. 4, nota 22.

-1 lenca: 'tortilla grande cocida al rescoldo', voz proveniente del veliche (o mapuche insular), segun Alejandro CaÑas P., quien documenta lleuca la tortilla de h.arina cocida en la ceniza o al horno" ("Estudios de la lengua veliche", en Ciencias 
Como éste tenía una perrita tan engreída, se fue con su perrita, pues.

Entonces, en el camino, ya le dio apetito y... y se sentó a servirse... a servirse un pedazo de... de leuca. Y entonces la perrita le empezó a hacer cariño, entonces dijo él:

-Más, más hambre tendrá la perrita que... que mí ${ }^{\top 2}$.

Así es que le dio la... la tortilla a la perrita... La perrita se llamaba Paula.

Entonces, al rato, claro, al rato quedó mirando... Al rato, la perrita se empezó a m... a mover, y al rato empezó a patalear. Y... y murió la perrita, pues.

Entonces, es que dijo:

-Bueno, ¿cómo es esto?

En eso estaba, mirando a su perrita $\mathrm{m}$... ya muerta, cuando vienen dos jotes $\mathrm{y}$ se paran encima de la perrita, y se com... comienzan a comer la perrita los jotes, pues.

Entonces, al rato, los jotes, ya empezaron a patalear también y... y también murieron, pues. Entonces e... él que dijo (de por ahí empezó a pensar la adivinanza que $y$... que dijo):

- Paula mató a dos - la perrita había matado a dos, pues.

Entonces, él ya tenía hambre, entonces es que dijo:

—iPuchas ${ }^{3}$ ! Voy a... voy a cocinar los jotes, yo.

Así es que empezó a... a cocinar los jotes y a hacerlos el asado. Cuando en eso ${ }^{7+}$, estaban..., estaban ya casi cocidos los... los dos jotes ya, cuando llegan siete bandidos y... y le quitaron el asado, pues... ¿m? Él no comió nada. ¿M, m?

Entonces, al rato, los siete, los siete bandidos también empezaron a morir, pues.

Entonces, de ahí empezó a estudiar éste, es que dijo:

-Paula mató... No, Leuca mató a Paula y Paula mató a siete.

Ahí lo iba él estudiando.

Bueno, y de ahí, caminó harto. Iba pasando en un puente, cuando, había un río ahí y mira para abajo: que en el río iba un caballo muerto, que lo llevaba la corriente del río y iban dos, tres jotes encima de... del caballo.

Entonces, es que dijo, empezó a (decir):

- Paula mató a dos... No, "Leuca mató a Paula, Paula mató a dos y dos mató a siete; me fui por lo duro, me encontré en lo blando y encontré un cadáver que tres frailes le iban cantando" (que era... que eran los jotes que iban encima del caballo, pues).

Entonces, ahí anduvo, anduvo, harto más. Y éste ya no...no... no tenía ni una cosa más y llevaba una escopeta. Y... y de ahí, vio, vio, vio una liebre ¿̇m? No, este animal es una coneja... Entonces, dijo:

- Voy a tener que matarme la coneja no más y comérmela.

Porque ya no... no... no podía más del hambre. Así es que le disparó a la coneja y la coneja andaba preña(d)a. Entonces, entonces, no mató a la coneja, como el...

naturales, antropológicas y etnológicas, vol. XI de los Trabajos al IV Congreso Científico celebrado en Santiago de Chile del 25 de diciembre de 1908 a 5 de enero de 1909, Santiago, Imprenta Barcelona, 1911, pp. 143-329; vid. p. 293).

$\neg$ Nótese el uso de la forma pronominal mí en frase comparativa ( más... que mî), donde se espera el empleo de yo. Cfr. Ch. KaNY, op. cit., p. 130.

3 Cfr. cuento núm. 4, nota 21.

${ }^{74}$ cuando en eso: loc. adv. equivalente a 'entonces'. 
del susto de la coneja del disparo, saltaron dos conejitos nuevos, pues. Entonces, ahora para cocerlos, pues. No tenía leña, no tenía nada. Y llevaba un paquete de libros, libros sagrados es que, libros católicos, fíjese la... Que dijo:

- Y, ahora, ¿cómo cuezo la carne?

Y... y "lo" 75 coció con... con los libros sagrados esos, con los libros que llevaba. Así que, listo ya:

- Paula mató... "Leuca mató a Paula, Paula mató a... a dos y dos mató a siete; me fui por lo duro; me encontré en lo blando y encontré un cadáver que tres frailes le iban cantando; apunté el ${ }^{76}$ que vi; maté el que no vi y comí carne recién nacida, con palabras sagradas" ¿m?

Je, je, je! Comió, com... pal... el que... carne recién nacida, con palabras sagradas, porque "lo" coció con ... con los libros sagrados que llevaba.

Y... y de ahí se fue a(do)nde el rey a decirle la adivinanza, pues.

Entonces, llegó (d)onde el rey y lo hizo en tres... en tres bases, la adivinanza. Primero le dijo, al rey: a siete"

-Maté a... o "Leuca mató a Paula, Paula mató a dos, y dos mató a ... dos mató

Ya, ahí hizo una base y el rey no "lo" pudo adivinar, pues.

Después le hizo, le hizo en tres bases; después de ahí le dijo:

- "Me fui por lo duro, me encontré en lo blando y encontré un cadáver que tres frailes le iban cantando".

Tampoco el rey "lo"... "lo" adivinó, pues.

Después, la última, no más:

"Apunté el que vi y maté el que no vi y comí carne recién nacida, con palabras sagradas". Ya. Total que el rey no adivinó ninguna de las tres adivinanzas, pues. Entonces, el rey que le dijo:

-Bueno, hijo, no te... no... no te he adivinado ninguna adivinanza, te voy a hacer otra promesa: Eh... Vas... vas que... a dormir en una misma pieza con la... con la princesa, con mi hija.

Y ella, la princesa, estaba... tenía... estaba de novia con un príncipe. Entonces:

- Van a dormir los tres, en la misma pieza. Y el que amanezca, mañana, abrazado con ella, o acostado con ella va a ser su marido, ¿m?

Entonces, que el... el cabro ${ }^{`}$, él es que le dijo:

- ¿Cómo lo hago esto?

Como ya andaba con plata ${ }^{-8}$, que se fue a... a una pastelería y fue a comprar unos manjares de los más buenos ${ }^{79}$ que había.

Entonces, se acostaron los tres, pues, en una cama: la princesa y los dos, el príncipe y... y él, pues.

Bueno, a él lo echaron... lo echaron por los pies, pues ¿m? Je, je, je, je!

Entonces, lo que hizo éste, en la medianoche, se levanta así, cuando ya están durmiendo los dos otros, ¿no?. se levanta y empezó a hacer su co... como su

- El clítico lo neutraliza aquí la distinción genérica y así aparece varias veces en el relato. Cfr. cuento núm. 9, nota 60.

") Cfr cuento núm. 0 , nota 35.

' cabro: metáfora familiar en Chile con referencia al 'niño o muchacho' (cfr.

R. OROZ, op. cit.. pp. 415 y otras); en el texto hace referencia a un 'joven' pretendiente.

" plata: cfr. cuento núm. 5, nota 24 .

$\checkmark$ más buenos: 'mejores'. 
necesidad, así hacer. Y... y tenía los bolsillos llenos de confites, de ésos. Entonces ahí empezaba a comerse... comer confites éste.

$\mathrm{Y}$, en eso, se "dispierta" ${ }^{80}$ el príncipe y le dijo:

- ¿Qué estás haciendo?

—PUchas ${ }^{81}$ ! —es que dijo- estoy haciendo mi necesidad.

- Y, ¿cómo lo estás haciendo?

— ¡Bah!, me lo estoy comiendo —es que dijo jje, je, je!

Entonces el príncipe (es)taba... (es)taba con la misma también, pues. Así que se levantó el príncipe y... y empezó a hacer la misma talla que estaba haciendo el otro. ¡Ja!, ja!, Ja!

En eso se lev... se levantó el otro y se va a acostar con la princesa. ¡Puchas!, bien perfumado, pues.

Al rato llega el príncipe y iji! se va a acostar con la princesa y que le dijo:

- QQué!, ¡cochino, hediondo! —es que le dijo-. Estírate por los pies no más.

Total que amaneció abrazado con la princesa. Y el rey tuvo que darle la hija no más, por fuerza al otro día.

$Y$ hasta ahí se termina el cuento, pues.

Total que se casó, con... con la... con la princesa, pues.

\section{BIBLIOGRAFÍA (DE LAS NOTAS LINGÜÍSTICAS)}

academia Chilena Correspondiente de la Real. ACademia Espanol.a. Diccionario del babla chilena, Santiago de Chile, Universitaria, 1971.

CAÑAS P., Alejandro, "Estudios de la lengua veliche", en Ciencias naturales. antropológicas y etnológicas, vol. XI de los Trabajos al IV Congreso Científico celebrado en Santiago de Chile del 25 de diciembre de 1908 a 5 de enero de 1909 , Imprenta Barcelona, 1911, pp. 143-329.

CONTRERAS, Constantino: "El castellano rural de Osorno (a través de textos orales), en Estudios Filológicos, núm. 28, Valdivia, Universidad Austral de Chile, 1993, pp. 123-135.

KANY, Charles E., Sintaxis hispanoamericana, versión espanola de Martín Blanco Álvarez, Madrid, Gredos, 1969.

LENZ, Rodolfo, Diccionario etimológico de las voces chilenas derivadas de lenguas indigenas americanas, Santiago de Chile, Imprenta Cervantes, 1912-1914. (Hay reedición dirigida por Mario Ferreccio Podestá, Santiago de Chile, Editorial Universitaria, s/f.).

Oroz, Rodolfo, La lengua castellana en Chile, Facultad de Filosofía y Educación, Universidad de Chile, Santiago de Chile, Editorial Universitaria, 1966.

RABANales, Ambrosio, Introducción al estudio del español de Chile. Determinación del concepto de chilenismo, Anexo núm. 1 del BOLETIN DE FIlología de la Universidad de Chile, Santiago de Chile, Editorial Universitaria, 1953.

80 "dispierta": variante de despierta, por asimilación o influjo de la yod del diptongo tónico (cfr. R. OROZ, op. cit., p. 91).

81 Cfr. cuento núm. 4, nota 21. 